Braze, D., \& Gong, T. (to appear). Orthography, Word Recognition, and Reading. In E. M. Fernandez \& H. Cairns (Eds.), Handbook of Psycholinguistics: Wiley-Blackwell.

\title{
12 Orthography, Word Recognition, and Reading
}

David Braze and Tao Gong (Haskins Laboratories)

\section{Abstract}

Orthographies differ from one another in terms of their scripts and in the specifics of the mapping from script to linguistic unit. Orthographic depth, the complexity of the mapping from script to language, modulates the ease with which an orthography is learned. Within an orthography, the consistency or regularity of a particular spelling pattern will temper the difficulty with which written words containing that pattern can be recognized. There is hope for a unified cross-orthography account of visual word recognition, although details of how non-alphabetic writing systems (e.g., syllabaries, morphosyllabaries, alphasyllabaries) may be fit into theoretical frameworks built on a foundation of empirical work on alphabetic reading are not entirely clear. There is a substantial gap in the literature with regard to reading and literacy in languages that make use of non-alphabetic writing systems. This euro-centric bias in reading research continues to limit advances in our understanding of the potential for literacy as a universal human capacity.

Keywords: eye movements; computational models; lexical access; lexical representation; orthography; phonology; reading; writing systems

\section{Preliminaries}

The nature of connection between oral and written language has been worried over by researchers for decades, perhaps as much as a century (Huey, 1908). Huey credits V. Egger with the notion that "to read is, in effect, to translate writing into speech (Huey, 1908, p. 123)." Some 60 years later, this basic idea was well on its way to becoming a lynch pin of our modern understanding of the relationship between speech perception, printed word recognition and language comprehension. Alvin Liberman, in Kavanagh (1968), framed the idea somewhat differently when he wrote that "reading is in some sense 
parasitic on speech (p. 123)." This is to say that speech perception and reading are not wholly independent systems, but that they stand in different relations to Language. The medium of speech is privileged over that of writing in ways that are now widely recognized. In the history of our species speech precedes print; in the development of the individual, the ability to speak comes before facility with the written word, if the latter comes at all. In fact, speech and language development would seem to be biological imperatives whereas achieving skill with the written word is most definitely not.

The 'parasitic' nature of the relation between speech and print is such that the connection between writing and language is mediated by speech. For those writing systems that have served as objects of most literacy oriented research to date, the Alphabetic Principle underlies that connection. This mapping principle asserts that there is an explicit correspondence between orthographic characters and speech, specifically at the phonemic level of representation (Bloomfield, 1942). Mattingly (1972; also see Liberman, 1988; Liberman et al., 1989) posited that the acquisition of reading ability in an alphabetic writing system relies on explicit knowledge of the phonemic structure of a language (phoneme awareness), and that that knowledge does not follow automatically from being a competent speaker of the language. Subsequent experimental work has largely confirmed Mattingly's surmise about the connection between meta-linguistic awareness of phonemic structure and the development of alphabetic literacy (e.g., Byrne et al., 2000 ; Bowey, 1995; Oakhill \& Cain, 2011). We will see that there is, moreover, reason to believe that language/orthography appropriate variations of the Mattingly's alphabetic mapping principle and metalinguistic awareness may be important to the mastery of any type of writing system.

Implemented cognitive models of word recognition that are most relevant to discussions of reading comprehension integrate perception of external language both by ear and by eye. So, it is critically important to have some common terminology for talking about relationships of writing to speech and language. Perfetti et al. (2007; also Coulmas, 1989) distinguish among scripts, writing systems and 
orthographies. In their terms, a script is simply a set of symbols, the visual aspect of writing, independent of any association with linguistic elements. Writing system refers to the nature of the basic mapping from symbols to linguistic units; an orthography is a specific language-to-script mapping. So, alphabetic writing is one kind of writing system, as in the Korean Hangul orthography; syllabic writing is another; Japanese Kana is a possible example, although it may be more properly considered a moraic system as syllable weight is also significant in this writing system. In the first case the fundamental design principle is to map symbols to phonemes, and in the second the mapping is from symbols to syllables. It is possible for an orthography to make use of more than one kind of mapping. There are various ways in which that can occur.

For example, some have proposed that writing systems used for many Sinitic languages (languages of the Sino-Tibetan language family, e.g., Mandarin, Cantonese) are fundamentally morpho-syllabic in nature (Coulmas, 1989). Which is to say that each character is associated with a unit of meaning and a monosyllabic pronunciation. The large majority of characters/graphemes in these morpho-syllabic writing systems are composed of two elements, a 'phonetic' element associated with pronunciation of a syllable and a 'radical' which serves a morpho-semantic purpose. Albeit, single element characters are not uncommon, and three element characters occur as well; each character, regardless of constituency, corresponds to a single syllable at the phonological level. There are conventionally 214 radicals in the 'simplified' character set used in the People's Republic of China. While the number of symbols occurring as phonetic elements is somewhat less clear, there may be on the order of 800 to 1000 in common use (DeFrancis, 1989). In the case of grapheme-to-morpheme mappings, the relationship is generally one-toone, while for grapheme-to-syllable mappings the relationship is typically many-to-one, there being many more graphemes than syllables. For example, consider some examples from the 'simplified' character set used for writing Mandarin in the Peoples Republic. The character 水 is a single element grapheme that corresponds to the word meaning 'water' (pinyin shui3). In modified form this character 
serves as the semantic radical in more than a dozen two-element characters and the meaning of many of those has a relatively clear association with 'water': 江 ('river'; pinyin jiang1), 洒 ('to sprinkle'; pinyin sa3), 漏 ('to leak/leaky'; pinyin lou4). The combining form of 水 can be seen at the left hand side of each character, * . Next consider a few characters which all contain as their radical the character for 'person', 人 (combining form 亿 ): 傲 ('proud/arrogant'; pinyin ao4), 仅 ('only'; pinyin jin3), 仿 ('to copy/to imitate'; pinyin fang3), 值 ('to value'; pinyin zhi2). Here, any semantic relationship among the words denoted by characters containing the 'person' radical is considerably less clear. Other radicals may have an even more obscure relationship to the meanings of words denoted by the attendant characters. According to DeFrancis (1989) many "often offer no real semantic information at all and merely serve to differentiate one character from another, as do our spelling distinctions in hair and hare."

The phonetic components of characters are by contrast considerably more informative, although far from transparent. For example, the phonetic element on the right (square with vertical stroke) in the character 钟 ('bell/timer/alarm'; pinyin zhong1) is identical in pronunciation to the phonetic itself when used standalone (中, 'in/within/during'; pinyin zhong1). As a component of other characters it is associated with similar but not identical pronunciations, as in: 冲 ('to charge in battle/to flush (toilet)'; pinyin chong1). More extreme examples of contextually determined pronunciation are not uncommon. Consider 淑 ('virtuous'; pinyin shu1) and 椒 ('pepper', pinyin jiao1), whereas their phonetic component, 叔, is pronounced shu1. The phonetic component of a character often provides a helpful clue as to its pronunciation, as when 皮 ('leather/skin'; pinyin pi2) is used as a phonetic in 披 ('to drape over one's shoulder'; pinyin pi1), or 坡 ('slope'; pinyin po1), or 跛 ('lame'; pinyin bo3). While this sort of inconsistency is common, DeFrancis (1989) estimates that the phonetic elements in about 2/3 of characters yield useful cues as to their pronunciation. Insofar as orthographic symbols map to phonology at the level of the syllable and to meaning at the level of the morpheme, then metalinguistic 
awareness important to acquisition of literacy in Sinitic languages might, arguably, target those two levels of analysis, rather than the phoneme as in alphabetic writing systems (Wang et al., 2015; Zhang et al., 2012; but also see Newman et al., 2011).

Two additional points about Sinitic writing systems that are not obvious from the foregoing should be noted here. First, contrary to the examples just given, most words in Mandarin are written with two or more characters. A second feature, setting the Chinese orthographies apart from the more familiar European ones, is that in writing connected text there is no explicit indication of word boundaries (more on this later).

A different type of duality in mapping can be found in the Korean Hangul system. This is fundamentally an alphabetic system in that graphemes map to phonemes, but when written, graphemes are arranged in groups or blocks that correspond explicitly to syllables, with each block containing two to six graphemes (Coulmas, 1989). For example the name of the writing system, rendered in Korean, is 한 굴. The leftmost block consists of three graphemes: 흐/h/ (top-left), ㄱ/a/ (top-right), and ᄂ $/ \mathrm{n} /$ (bottom). The right block also consists of three graphemes, arranged vertically: $\neg / \mathrm{g} /,-/ \mathrm{u} /, 2 / \mathrm{I} /$. Here the dual nature of the mapping is entirely to do with different aspects of phonological structure. One might contrast this with the Vietnamese orthography, which is a romanbased alphabet, with the peculiar feature of using spaces to separate syllables and moreover lacking any specific indication of word boundaries. Modern Korean uses whitespace to mark word boundaries.

A third example of complex mapping can be found in orthographies used for writing most of the languages, of both Sanskritic and Dravidian origin, on the Indian sub-continent. These orthographies are sometimes called alphasyllabaries and their individual graphemes are referred to as akshara (Padakannaya \& Ramachandra, 2011). While there is considerable diversity in this large group of orthographies they share a set of common characteristics (Coulmas, 1989): (a) each basic grapheme 
represents a consonant and an inherent vowel, and the inherent vowel is the same for all basic graphemes; (b) vowels other than the inherent vowel are represented by diacritics applied to basic graphemes; application of a diacritic replaces the inherent vowel with that represented by the diacritic; there is typically a special diacritic which suppresses the inherent vowel altogether; (c) consonant clusters are represented by ligatures of basic characters, and all but the final grapheme in a ligature loses its inherent vowel; (d) there is a set of graphemes used for initial vowels in syllables lacking a consonant onset. For example two basic akshara from the Gujarati alphasyllabary are $\mathrm{r}$ and 5 , representing the CV syllables /ta/ and /ka/; the graphemes cannot be decomposed into separate elements corresponding to the consonant and vowel. Diacritics can be applied to these basic akshara to replace the inherent vowel with another, for example: તે/te/, તિ/ti/, તો/to/, તુ/tu/, and કે /ke/, કિ/ki/, કો /ko/, ક /ku/. The individual akshara (basic grapheme plus diacritic) in these examples represent open syllables which can be broken down into phonemic components, although the diacritic vowels cannot stand alone (Padakannaya \& Ramachandra, 2011). The diacritics are shown here, with the position of the dotted circle indicating the approximate relative location of the basic akshara: $/ \mathrm{e} /, \mathrm{ি} / \mathrm{i} /, \mathrm{0} / \mathrm{o} / \mathrm{3}$ /u/. Further, the inherent vowel can be suppressed with a special purpose diacritic called a virama, yielding a monophonemic (consonantal) grapheme: + / $\mathrm{t} /$, \&् /k/. This alphasyllabic system differs from both the fundamentally alphabetic Korean Hangul system, described previously, and Japanese Kana in which each basic grapheme represents a syllable or mora in holistic fashion; Kana graphemes cannot be further analyzed into phonemic elements. Although, it has been argued that grapheme-to-phonology mappings in aksharic orthographies allow for (or even require) isolation of phonemes, and that this is evidence that such systems should be considered fundamentally alphabetic in nature (Rimzhim et al., 2014). 
Finally, we previously observed that the Chinese morpho-syllabic writing systems do not explicitly mark word boundaries, in contrast to the convention of inter-word spaces in European orthographies and elsewhere. Alphasyllabaries can be found in either camp. Gujarati makes use of spaces (probably the most common case for this type of writing system) while the Thai alphasyllabary does not indicate word boundaries.

As noted, the term orthography encapsulates details of the mapping from symbols to language elements. These details will necessarily include things like the specific symbol set, the specific linguistic units to be mapped (whether they be syllables, phonemes, morphemes or some admixture), and the specific mappings between linguistic units and symbols. Change any detail of the script, the linguistic units, or the mapping between them, and you have a different orthography. As a point of comparison, consider the cases of English and Dutch. The standard written forms of both languages use the same script, the same 26 grapheme set derived from the Roman script (leaving aside the issue of accents). However, because the phonemic structure of the two languages differs (as a result of language change over time), so too do many of the specific mappings between phonemes and graphemes, although there is some overlap due to historical connections between the languages and the origins of the script.

Regardless of the specific details of script and language, an ideal orthography would be one in which the mapping from symbols to linguistic units is one-to-one and perfectly consistent. But orthographies vary considerably in how closely they approximate the ideal (Lukatela et al., 1980). The relative consistency of mapping from symbol to linguistic unit is referred to as orthographic depth (Lukatela et al., 1980). Deep orthographies have complex mappings (e.g., standard writing conventions for English, Mandarin Chinese and Hebrew), while shallow orthographies more closely approximate the ideal one-to-one mapping (Korean Hangul, Japanese Kana, Spanish alphabet). The Orthographic Depth Hypothesis holds that shallower orthographies will be easier to learn due to their more consistent mappings from grapheme to linguistic unit, and that in such writing systems phonology will play a more 
prominent role in lexical access than will be the case for deeper orthographies (Frost et al., 1987; Frost \& Katz, 1989; Katz \& Frost, 1992; Rao et al., 2011; Schmalz et al., 2015).

Orthographies (specific language-to-script mappings) with considerably greater overlap than that of the Dutch/English case mentioned above are not unusual. These may arise due to systematic differences in language usage across speakers of a single language; differences in pronunciation, word choice and even grammatical construction, are commonplace. Such differences are often linked to a speaker's identification with a particular social group that may be defined in part by culture or social class or geography (Wolfram, 2006). Details of a non-mainstream language variety that differ from the mainstream variety may complicate the acquisition of literacy by individuals or groups whose usage is not well-aligned with the mainstream. For example, it has been hypothesized that this kind of mismatch, with regard to contrasts in pronunciation between African American English (AAE) and Mainstream American English (MAE), may form an additional obstacle to the acquisition of literacy for children whose home dialect is AAE (Cunningham, 1976; Labov, 1995; LeMoine, 2001). While the evidence available for this particular case of orthographic mismatch finds little support for the hypothesis, researchers point out that children whose home dialect is predominantly AAE typically have enough knowledge of MAE by the time they reach school to mitigate any putative mismatch disadvantage (Patton Terry et al., 2010; Patton Terry \& Scarborough, 2011; Patton Terry, 2012). The question remains as to whether children coming from more insular non-mainstream language backgrounds might be hampered in their acquisition of orthographies tailored to unfamiliar language standards.

The terminological distinctions and conceptual foundation developed above give us the wherewithal to avoid certain confusions and ambiguities that are not unusual in even erudite discussions of 'writing.' For example, the Mandarin language is rendered in print using at least three different orthographies grounded in two different design principles: morpho-syllabic traditional characters in Taiwan, morpho-syllabic simplified characters in the Peoples Republic of China and 
alphabetic pinyin in the early grades in both (Cheung $\& \mathrm{Ng}, 2003$ ). In fact, it may not be unusual for the same language, or minimally different language varieties, to be written with very different scripts, as in the cases of Serbian/Croatian (Feldman et al., 1985; Lukatela \& Turvey, 1980) and Hindi/Urdu (Rao et al., 2011). Moreover, two orthographies may be superficially similar in that they make use of the same script, yet map to languages that differ subtly (AAE/MAE) or markedly (English/Dutch) from one another.

Details of an orthography may have significant consequences for ease of lexical access by eye, the process by which the mental representation of a word's meaning or phonology becomes available for use. Evidence supports the hypothesis that the depth of an orthography modulates the ease with which beginning readers acquire it (Ellis et al., 2004; Seymour et al., 2003), or the ease with which fluent readers access the words that they know (Katz \& Frost, 1992; Paulesu, 2006). Within an orthography, adult readers are faster to identify words with regular orthographic patterns vs. irregular ones and this difference is greater for words that are less familiar (e.g., Katz et al., 2005; Van Orden, 1990); other research shows that target letter identification is easier/faster when the letter string that contains the target is a word, vs. nonword (e.g., Reicher, 1969; Wheeler, 1970). The ability to account for such effects is the minimum bar that must be cleared by any model of visual word recognition.

\section{Models of written word recognition}

What follows is an admittedly incomplete and superficial survey of written word recognition models. The aim of such implemented models is to capture details of connections between single word recognition in print and speech modalities. A related issue, that of how to understand the relationship between lexical access and fluent reading of connected text, is discussed in the following section. A recurring theme in most models of visual word recognition is the presence of two modes of access to a lexical representation, given a particular orthographic stimulus. This dual path characteristic seems 
critical to accounting for the influence of certain lexical characteristics on the time course of word identification. The typical goal of a model is to predict human response times or accuracies for experimental tasks like word naming or lexical decision. In a typical naming task a participant is presented with the written representation of a single word and their charge is to simply pronounce it quickly and accurately. In a lexical decision task the participant is given an orthographic string, which may or may not represent a real word in the language at issue. Their task is to make a speeded judgement for each item as to whether or not it represents a real word and to press a button indicating that choice. A model's ability to emulate typical human performance is the standard against which it is judged. A significant limitation of essentially all current models of visual word recognition is that their organization typically incorporates specific assumptions about the target orthography and that this greatly limits the possibility of a completely general explanation of how word reading proceeds across orthographies (Rueckl, 2016). A recent collection of papers revealing the complexity and depth of the issues surrounding visual word recognition can be found in Grigorenko and Naples (2008).

In the early days of mechanistic word recognition models, Morton proposed that the mental lexicon could be simulated as a set of "logogens," essentially word detectors (Morton, 1969). Each logogen accumulates evidence in the form of sensory input or contextual information for the presence of a particular word. Only when evidence for a word exceeds a threshold does information associated with the word become available for subsequent processing (e.g., naming the word, or integrating it into a phrase). The earliest Logogen model held that lexical representations and mechanisms of access were amodal in all but the most superficial of sensory aspects. As such, a central prediction of the model is that there should be similar levels of lexical priming across modalities. Priming is an increase in speed or accuracy of word naming or lexical decision that occurs when the word under consideration is similar in some way (form or meaning) to a word that has been seen previously. The early Logogen model predicted that facilitation should be about equal whether a printed item was used to prime recognition 
of a spoken one, or vice versa. When data from experimental work with humans proved inconsistent with those predictions, later Logogen variants incorporated modality specific routes to the lexicon and constrained the potential for interaction between them (Morton, 1979, 1980). Other architecturally similar models emerged about this time in attempts to account for aspects of word recognition where logogen-based models failed. The Cohort model of speech recognition, for instance, dispensed with explicit thresholds for word detection, but retained the concept of individual word detectors, as well as the commitment that word-recognition is all-or-nothing; graded accumulation of evidence for words has no effect on subsequent processing until such a time as a word has been uniquely identified (MarslenWilson \& Welsh, 1978).

The Dual Route Cascaded Model (DRC) of word identification is, like later versions of the Logogen model, explicitly designed to account for findings that supported a dissociation in modality specific paths to the lexicon, whence dual-route (Coltheart et al., 1993; Coltheart \& Rastle, 1994). One path to the lexicon is direct, relying on learned associations between orthographic forms, and phonology and semantics (the lexical route). A phonological path affords access to the lexicon by way of intermediate phonological representations which are computed, or assembled, on the basis of learned orthographyphonology mappings. The correspondence rules that make this possible are built into the DRC, so it is capable of simulating skilled reading only; it is not a model of reading skill acquisition. However, mechanisms have been proposed for learning of grapheme-phoneme correspondence rules (Coltheart et al., 1993; Pritchard et al., 2016). The path to the lexicon by way of assembled phonological representations, while indirect, has the advantage of allowing access to words that are part of a reader's speech vocabulary, but whose orthographic representation is unfamiliar. It may also be critical to the ability to learn entirely new words from print (De Jong \& Share, 2007; Share, 1995; Share, 2011). Assembled phonology has the disadvantage, more so for some orthographies than others, that if a word's orthography-phonology mapping is inconsistent with the regular patterns for the orthography, 
then it may be difficult or impossible to derive a phonological form that is sufficient to support lexical access.

The DRC approach differs from the Logogen approach in that DRC models are cascaded, organized such that the output of each subprocess in a model is a set of continuous values that are always available for processing at the next level (McClelland, 1979). So DRC models provide for graded lexical activation across levels of processing. Word detection is neither thresholded nor all-or-nothing with regard to making lexical information available for subsequent processing. Further, consistent with the Interactive Activation Model (IAC) of printed word detection (McClelland \& Rumelhart, 1981), information flow between subprocesses in the DRC can be bidirectional. The IAC and the DRC are explicit in representing words as nodes. As such, they can be considered symbolic systems. Nodes in the DRC are vaguely similar to logogens in the sense that, for each word in the lexicon, there is an individual node uniquely responsible for reflecting the current state of evidence for that word. Unlike logogens, this evidence is available to other subprocesses on a continuous basis (McClelland \& Rumelhart, 1981; Coltheart et al., 2001).

A fundamental premise of the DRC is that expert readers use both lexical and assembled phonological pathways to the lexicon during word recognition. Assembly of accurate phonological representations on the basis of orthographic input requires that the word under consideration conforms to the regular spelling patterns of the orthography. The assembled pathway will allow for the construction of a phonological representation even in the absence of a lexical entry, necessary when the word is unknown (perhaps a pseudoword); the assembled phonological representation can serve for naming the novel item. For known words, both pathways will be available. The lexical route provides a means to access a stored phonological representation without having to assemble it entirely on the fly. This is advantageous when a word's spelling does not conform to the regular spelling patterns for the orthography. However, it should be observed that an instance of phonological access in the DRC for the 
purpose of reading a known word aloud is not the result of a winner-take-all "race" between assembled and lexical routes, but rather a product of both (Coltheart et al., 2001; Frost, 1998). In human performance, words whose spellings are in conflict with the regular spelling patterns of an orthography (irregular or exception words) result in longer reaction times for naming and identification, and trigger more errors than words with rule-governed spellings (Andrews, 1982; Treiman et al., 1995), and the DRC captures these effects. This conjoint influence of the two paths, and their distinct mechanisms, allows for established lexicality effects in word and nonword naming, and also an explanation for the effect of spelling regularity being less evident in lexical decision than in word naming (e.g., Hino \& Lupker, 2000; Andrews, 1982).

The DRC model was developed specifically to account for facts of printed word recognition in English, and it has been extended with some success to other alphabetic orthographies (Ziegler et al., 2000; Ziegler et al., 2003). However, Coltheart et al. (2001) aver that “The Chinese, Japanese, and Korean writing systems are structurally so different from the English writing system that a model like the DRC model would simply not be applicable (p. 236)." The bases for parts of this claim are questionable: Korean Hangul is a fundamentally alphabetic orthography and so it's difficult to see why the DRC should not be expected to cover it. Regardless, Coltheart and colleagues make the strong claim that reading in alphabetic orthographies proceeds via altogether different mechanisms than reading in non-alphabetic orthographies. An overview of the development, structure and capabilities of the DRC can be found in Coltheart et al. (2001).

The Triangle Model (TM) of Seidenberg and colleagues (1989) is yet another influential framework for understanding word identification processes. It follows on earlier interactive models of word recognition (McClelland, 1979; McClelland \& Rumelhart, 1981; Rumelhart \& McClelland, 1982) and is strongly committed to non-symbolic lexical representations. Words are encoded as distributed patterns of activation in a connectionist network; there are no lexical nodes representing individual words, as 
exist in the DRC. The basic TM has seen several revisions since its introduction. In all versions, printed word identification proceeds through a combination of direct connections between orthography and semantics, and a phonologically-mediated pathway from orthography to phonology to semantics. Orthographic input initiates patterns of activation that flow simultaneously through each pathway. Any given input will engender a distributed representation consisting of phonological, semantic and orthographic information that corresponds to a lexical identity. Phonological access for both words and nonwords arises via the same pathways in the network. Flow of activation through the network from orthography to phonology can be viewed as roughly analogous to the lexical and assembled routes of the DRC (Harm \& Seidenberg, 1999; Harm \& Seidenberg, 2004; Plaut et al., 1996). However, the distributed nature of lexical representations in the TM stands in distinct contrast to the DRC, with its local unitary representation of memorized word forms and production rules for decoding novel words. Further, the TM relies on the single mechanism of spreading activation through a connectionist network to derive its explanatory power.

A crucial difference between the two approaches is highlighted by considering the difference between orthographic regularity in the DRC, a categorical distinction among words, and orthographic consistency in the TM, a continuous graded property of words. The spelling of a word is either regular, its pronunciation is correctly determined by grapheme-phoneme correspondence rules, or not (MINT is regular; PINT is not), while orthographic consistency is graded in the sense that it can take values between 0 and 1. For example, the English spelling pattern -INK is consistent in that only one pronunciation is possible (e.g., rink, fink, mink), whereas the spelling pattern -AVE is not (save, pave etc., versus have). Consistency of a word is typically defined over its orthographic neighborhood, which is to say those words that are spelled similarly to it (Glushko, 1979). The -INK neighborhood is perfectly consistent, while the -AVE neighborhood is less so. Another important difference between the TM the DRC model is that the former directly incorporates a learning mechanism that allows it to induce 
regularities in orthographic mappings, rather than relying on a set of pre-specified correspondence rules (Seidenberg \& McClelland, 1989).

It is interesting to note that orthographic consistency may have a relatively straightforward analog in the Mandarin morpho-syllabary. There, consistency can be defined as the congruence in pronunciation among characters sharing a phonetic component (Shu et al., 2003). Several studies have reported effects of consistency, thus defined, on character naming that seem to cohere with more established results from word naming in alphabetic orthographies (e.g., Hsu et al., 2009; Lee et al., 2004; Li et al., 2011). One recent effort to fit data from readers of Chinese using a modification of the Triangle Model has also met with some success. There, Yang and colleagues (2009) used a connectionist model to predict an interaction between frequency and consistency in Chinese word (character) naming, similar to that found in English word naming, in addition to an effect of regularity peculiar to Chinese. Data from a behavioral study of character naming by Chinese speakers subsequently confirmed their predictions (Yang et al., 2009).

Variations on the Dual Route Cascaded Model and the Triangle Model are perhaps the strongest rivals among implemented mechanistic models of visual word recognition, with the edge going to the TM due to its explicit incorporation of a learning mechanism and to its stronger potential for applicability across writing systems. Yet, it must be acknowledged that most work toward understanding the reading process has focused on word recognition in alphabetic writing systems and more often than not rather explicitly on reading English (Share, 2008). That is certainly true of most of the research involving the models described in the preceding paragraphs. However, as Share observes, the English orthographies are rather unusual among alphabetic writing systems, being especially deep orthographies. Inferences derived from research on English speakers may not generalize well even to other alphabetic systems, and generalization to other types of writing systems is even more questionable. Share (2014) raises a somewhat related issue that he calls 'alphabetism' in reading 
research. Alphabetism is the often unspoken assumption that alphabetic writing systems are inherently superior to those built around other design principles (e.g., syllabaries, morpho-syllabaries, alphasyllabaries). As Share observes, this assumption has been largely unexamined and seems to stem from a European bias in the reading research literature. As we have seen, orthographies show considerable diversity, and some researchers have questioned whether a unified account of reading across languages and orthographies is even possible (cf. Coltheart et al., 2001). Both issues call for a better understanding of the diversity of writing systems and their implications for the process of visual word identification and reading in general.

The Lexical Constituency Model (LCM) reflects the recent move toward extending the coverage of mechanistic models of word recognition beyond alphabetic writing systems (Perfetti et al., 2005). The model is motivated by emerging evidence that Chinese readers are sensitive to the phonological information provided by their writing system, that activation of phonological information by character graphemes can be as fast and automatic as activation of semantic information (Zhang \& Perfetti, 1993; Perfetti \& Tan, 1998; Xu et al., 1999). In the implemented version of the LCM, inputs are encoded representations of characters. These connect to an orthographic level of representation, which itself has direct connections to a semantic level of representation and to a phonological level, the latter with separate encoding of syllabic onset (all phonemes in a syllable up to, but not including the vowel) and rhyme (those phonemes from the vowel onward) and tone. Further pathways also connect semantics to the syllable components represented in the model's phonological level. It bears repeating that a crucial difference between activation of phonological information by way of Chinese orthographies and similar initiation of phonological processing in alphabetic writing systems is that in Chinese the phonological units mapped to graphemes are syllables, not phonemes. So, any phonological route to the lexicon cannot proceed by way of phonological assembly of phonemic constituents, as is presumably the case with alphabetic systems. Therefore, Perfetti et al. (2005) make the assumption that written word 
identification necessarily includes "the recovery of a phonological object and its associated nonphonological components (p. 46)," even for writing systems like those used in Mandarin and other Sinitic languages. Perfetti (2007) reiterates the widely held notion that the mental representation of a word consists of an intersection of phonological, semantic and orthographic information. This general view is consistent with both distributed (e.g., the Triangle Model) and symbolic models (e.g., the DRC Model) of written word identification, including the Lexical Constituency Model. Under this view, the process of word recognition, or lexical access, becomes that of using available evidence, in the form of a written representation, to recover additional task-relevant components of a target word's lexical representation (Perfetti et al., 2005).

These models and others focus on visual recognition of individual words. At the same time, it must be acknowledged that comprehension of connected text necessarily involves additional work beyond word recognition including, at least, derivation of syntactic (e.g., Rayner et al., 1983; MacDonald et al., 1994; Frazier \& Clifton, 1997; Hale, 2003) and ultimately discourse representations (e.g., Kintsch \& Kintsch, 2005 ; Marslen-Wilson et al., 1993; McKoon \& Ratcliff, 1988). The Dual Route Cascaded, Triangle and Lexical Constituency frameworks focus on word recognition, treating post-lexical integration as a black box with the assumption that whatever mechanisms are responsible for syntactic and discourse processing of spoken language are used also for print language input. Any potential differences in print and speech processing above the level of the word would seem to derive from the fundamental contrast in the temporal persistence of print and speech signals, a distinction that is independent of any specific orthography.

\section{Models of gaze behavior during reading}

In order to read connected text, a necessary sequel to visual recognition of individual words is the scanning behavior that moves the eye from one word to the next as the linguistic content of the text 
is processed. Scanning serves to move words across the fovea, the highest resolution portion of the visual field, for optimally efficient word recognition (Inhoff, 1989; Rayner, 1975; Rayner et al., 1982). The fovea extends about $2^{\circ}$ through the most central portion of the visual field, while an area of lesser acuity, the parafovea, extends another $3^{\circ}$ beyond the foveal limit. Words are identified more quickly and accurately in the foveal region, although information useful to the reader can be obtained for text in the parafoveal region as well (Rayner \& Morrison, 1981). For example, spaces indicating word boundaries are readily detectable in the parafovea (Sheridan et al., 2013; Slattery \& Rayner, 2013). Gaze patterns over text are characterized by two distinct phases: fixation, in which the point of regard is relatively unchanging, and saccade, which is a rapid shift of gaze from one position to the next (Rayner, 1998). Several models have emerged in which details of the coordination of gaze behavior with word recognition processes are proposed to explain facts about the nominal durations of gaze on each word as well as the distribution of fixation locations within a text.

There is some controversy as to whether eye movements are directly regulated by cognitive dictates of linguistic processes (Engbert et al., 2002; Reichle et al., 1998), or whether surface perceptual features of the text (visual features at the script level) are the primary governors of gaze patterns (McConkie et al., 1994; Reilly \& O'Regan, 1998). In the first instance, linguistic processes like word recognition or contextual integration have a direct role in driving gaze behavior, while in the latter case linguistic processes serve only to modulate gaze behavior that is primarily driven by low-level visual information, word length inferred from spaces between words, for example. Nonetheless, it is wellestablished that gaze patterns over text are influenced by text characteristics, from lexical to syntactic to pragmatic, as well as reader characteristics like decoding skill (Summarized in: Rayner et al., 2006; Staub \& Rayner, 2007; Rayner et al., 2013). The cognitively oriented model E-Z Reader model, which gives a direct role to linguistic processing (lexical access and contextual integration) in determining the timing and location of fixations over text (Reichle et al., 1998), will be the focus of this section. 
Reichle et al. (1998) introduced the E-Z Reader framework, or family of models, with the goal of accounting for interactions of visual processing, attention, and lexical processing in guiding the eye movements of readers (Reichle et al., 2006). It is important to understand that E-Z Reader models do not aspire to provide deep accounts of word identification, sentence parsing, or eye-movement control, but instead should be seen as an account of how the relationships among these processes drive the location and timing of eye movements over print. A central feature of the E-Z Reader framework, is that attention for the purpose of lexical access is allocated serially, to one word at a time. Lexical access is modeled as a two-stage process: a "familiarity check" presumed to focus on recognition of formal properties of the word (phonology) begins when attention is allocated to its visual features; a subsequent "completion" stage involves retrieval of syntactic and sematic properties of the word from memory (Reichle, Liversedge, et al., 2009). More specifically, the second stage can be seen as representing some minimal amount of processing that must be carried out for the current word before attention can be shifted to the next. Two factors influence lexical access times in the various E-Z Reader models. Word frequency, estimated through corpus counts, stands proxy for general lexical properties (e.g., familiarity, consistency). Predictability in context, typically operationalized as cloze probability, can be seen as an estimate of difficulty associated with integrating a word into its syntactic and semantic context. In earlier versions of E-Z Reader, post-lexical integration of a word into preceding context was not handled separately from the completion phase of lexical processing, whereas contextual integration receives more explicit treatment in more recent models (Reichle, Warren, et al., 2009).

A second key feature of the E-Z Reader framework is its decoupling of saccadic programming and execution, and lexical processing. Once the familiarity check is complete, saccade programming proceeds in parallel with the completion phase of lexical access. This sets up a race between substantial completion of lexical access and completion of the motor program which shifts gaze to the next point of regard. Design of the model is such that lexical access sufficient to release attention always finishes 
before saccade programming. Upon completion of lexical access, attention shifts covertly to the next word, while gaze lags somewhat. The first stage of lexical processing begins as soon as a word becomes the focus of attention. Variation in the magnitude of the lag between attention and gaze as they step through a text is a function of the difficulty of processing the current word, $n$. When $n$ is difficult, low frequency or low predictability, then the lag is shorter and so the duration of pre-fixation attention devoted to the subsequent word is shorter. This variable lag is the mechanism by which the model accounts for "spillover" effects such that fixation time on word $n+1$ is influenced by properties of word $n$ (Just \& Carpenter, 1978; Rayner et al., 1989; Warren et al., 2011).

In E-Z Reader, the time needed for saccade programming is a function of two random variables with fixed parameters, the first corresponding to a labile phase of programing, wherein the program can be influenced by external factors, and the second to a non-labile phase. Parafoveal processing of a word can also play a role in the timing of eye movements (Sheridan \& Reichle, 2015). In general, the choice of where to move the eyes is a function of the optimal viewing location of the next word (McConkie et al., 1988; McConkie et al., 1989; Vitu et al., 1990), plus a stochastic component to emulate error in the oculomotor program. Word skipping behavior can also be simulated by the model; E-Z reader will cause word $n+1$ to be skipped if its familiarity check finishes before the labile portion of the saccade program to shift gaze from word $n$ to $n+1$ is complete. In this case the program to fixate word $n+1$ is canceled and replaced by a new program to shift gaze to word $n+2$ (Pollatsek et al., 2006; Reichle et al., 2012). Simulations with E-Z Reader models by Reichle and colleagues discussed above have reproduced a number of benchmark phenomena from studies of gaze behavior in reading alphabetic orthographies, including effects of word frequency (e.g., Gong et al., 2016; Just \& Carpenter, 1980; Raney \& Rayner, 1995; Valle et al., 2013) and predictability (e.g., Braze et al., 2002; Husain et al., 2015; Kliegl et al., 2006) on reading times, and word length on fixation positions (e.g., Vitu et al., 1990; Joseph et al., 2009). 
In reading Chinese, just as for the alphabetic orthographies for which E-Z Reader models were first developed, word predictability in context and word frequency influence eye movements in expected ways: predictability is inversely related to fixation time (Rayner et al., 2005), as is frequency (Yan et al., 2006). However, the lack of any explicit indication of word boundaries in Chinese orthographies sets it apart from the European alphabets that have served as the forge for E-Z reader (a feature shared with some other orthographies, e.g. Thai, Japanese). This lacuna might increase the need for top-down information in extracting words from text in such writing systems. Evidence suggests that word boundaries in Thai, for example, are identified based on the distributional properties of graphemes (Kasisopa et al., 2013; Reilly et al., 2011), using mechanisms perhaps not dissimilar from those engaged by listeners in identifying words within continuous speech (e.g., Frank et al., 2013; Saffran et al., 1996). Some studies have asked whether inserting word-delimiting spaces into Chinese text would have a facilitative effect on reading, and the general finding is that the presence of such spaces either has no effect on reading times (Bai et al., 2008) or that reading times are indeed reduced (Hsu \& Huang, 2000b, 2000a). The same studies demonstrate that insertion of word-disrupting spaces has the effect of slowing reading times (also see Li et al., 2009). These rather surprising results would seem to indicate that reducing the need for top-down information in guiding eye movements has a facilitative effect even in orthographies where unspaced text is the norm. One effort to adapt E-Z Reader to reading Chinese assumes that readers have deterministic knowledge of word boundaries when reading conventionally unspaced text (Rayner et al., 2007). Given this somewhat unlikely assumption, the model is able to describe characteristic patterns of gaze over Chinese text with fair accuracy. That said, there is work to be done in understanding the mechanisms of word segmentation in orthographies that lack explicit cues. Some additional discussion of the problems for E-Z Reader vis a vis word segmentation and saccade targeting can be found in Liu et al. (2015). 


\section{Language comprehension and reading}

Language comprehension is the product of external sources of information, both linguistic and contextual, interacting with internal knowledge and processes. Regardless of whether the input modality is auditory or visual, the complexity of information and processes that generate a percept of linguistic meaning contribute to a state of affairs where, of necessity, theorists typically focus on generating testable models of component systems (e.g., lexical structure, lexical access, syntactic processing, discourse representation), rather than on soup-to-nuts models of comprehension as such. Some components of a comprehension model may represent greater theoretical and methodological challenges than others, or simply be better developed for a variety of reasons.

It will also be worthwhile to consider Gough and Tunmer's Simple View of Reading (SVR; 1986; Tunmer \& Chapman, 2012), which has been influential in framing work on development of reading comprehension and its connections to oral language comprehension and visual word recognition. The Simple View states that comprehension of written language is the product of two capacities: the ability to decode, or to access lexical representations by way of their print forms, and the capacity for general language comprehension (typically operationalized through measures of oral language comprehension). If an individual has good oral language skills, but no familiarity whatsoever with their language's written form, then they will have no ability to read; if decoding skill is less than perfect this will impose real limits on the ability to comprehend language in its printed form. Conversely, if an individual has good decoding skills (visual word recognition skills), then their ability to comprehend print will be limited by their ability to comprehend language in general, where the constraints may arise from limits on specific vocabulary or lack of familiarity with complex grammatical structures or discourse devices. Regardless, the SVR holds that the single crucial difference between efficient processing of written versus spoken language lay in the input modality of words. Once words are recognized, subsequent processing 
proceeds in the same manner regardless of whether the original modality was visual or acoustic; the mechanisms involved in parsing, mental model construction and inferencing are essentially amodal.

In this connection, Braze et al. (2011) present evidence from a neuro-imaging study of sentence processing in print and speech. They used functional magnetic resonance imaging to examine brain activity in experienced readers while they read or listened to matched sentences that were designed to challenge specific aspects of comprehension; input modality was a within-subject manipulation. The brain regions engaged by challenging materials, largely confined to the left inferior frontal gyrus and the left posterior superior temporal gyrus, correspond approximately to regions that previous studies had identified as being sensitive to differences in sentence complexity (e.g., Constable et al., 2004; Michael et al., 2001). Additional analyses confirmed that predominantly left-hemisphere frontal and temporal regions responded in a similar way to comprehension challenges posed by the experimental sentences regardless of whether they were presented in printed or spoken form. Their findings support the existence of an amodal language system which integrates linguistic inputs arising from different modalities such that speech and print engage a common underlying code (Braze et al., 2011; also see: Frost et al., 2009; Shankweiler et al., 2008).

There has been considerable work indicating that the two components of the Simple View, decoding and language comprehension, are correlated but nonetheless distinct capacities for a variety of populations and developmental stages (e.g., Braze et al., 2007; Braze et al., 2016; Catts et al., 2006; Dreyer \& Katz, 1992; Joshi \& Aaron, 2000; Landi, 2010). The SVR also makes an interesting prediction with regard to developmental changes in the specific contributions of oral language comprehension capacity and decoding skill. In early grades, where children are still learning to read, reading comprehension is clearly limited by a child's decoding skill, but as printed word recognition skills become automatized the importance of general language skills as a constraint on reading comprehension will increase and the importance of decoding skill as a limiting factor will decrease. The 
body of work in this area seems to confirm that supposition (e.g., Gough et al., 1996; García \& Cain, 2014). So, the idea that mechanisms of language processing are largely independent of input modality should be qualified by the impact of differences in reading skill regardless of the details of language or orthography.

\section{Conclusion}

Orthographies differ from one another in terms of their scripts, the visual characteristics of their graphemes, and in terms of the nature of the mapping from script to linguistic unit. Orthographic depth, the complexity of the mapping from script to linguistic unit, modulates the ease with which an orthography is learned, and within an orthography the consistency or regularity of a particular orthographic pattern will temper the difficulty with which written words containing that pattern can be recognized. There is some hope for a unified cross-orthography account of visual word recognition, although details of how non-alphabetic writing systems (e.g., syllabaries, morpho-syllabaries, alphasyllabaries) may be fit into theoretical frameworks built on a foundation of empirical work on alphabetic reading are not entirely clear. Indeed, there remains a substantial gap in the literature with regard to research on reading and literacy in languages that make use of non-alphabetic writing systems. This euro-centric alphabetism in reading research continues to limit advances in our understanding of the potential for literacy as a universal human capacity.

\section{Acknowledgements}

The authors are grateful to Jenna Duclos for assistance with preparation of this chapter. The authors' research is supported by National Institutes of Health grant R01 HD071988 to Haskins Laboratories. 
References

Andrews, S. (1982). Phonological recoding: Is the regularity effect consistent? Mem Cognit, 10(6), 565575. http://dx.doi.org/10.3758/BF03202439

Bai, X., Yan, G., Liversedge, S. P., Zang, C., \& Rayner, K. (2008). Reading spaced and unspaced Chinese text: Evidence from eye movements. Journal of Experimental Psychology: Human Perception and Performance, 34(5), 1277-1288. http://dx.doi.org/10.1037/0096-1523.34.5.1277

Bloomfield, L. (1942). Linguistics and Reading. The Elementary English Review, 19(4), 125-130

Bowey, J. A. (1995). Socioeconomic-Status Differences in Preschool Phonological Sensitivity and FirstGrade Reading-Achievement. Journal of Educational Psychology, 87(3), 476-487. http://dx.doi.org/10.1037/0022-0663.87.3.476

Braze, D., Katz, L., Magnuson, J. S., Mencl, W. E., Tabor, W., Van Dyke, J. A., Gong, T., Johns, C. L., \& Shankweiler, D. P. (2016). Vocabulary does not complicate the Simple View of Reading. Reading and Writing, 29(3), 435-451. http://dx.doi.org/10.1007/s11145-015-9608-6

Braze, D., Mencl, W. E., Tabor, W., Pugh, K. R., Constable, R. T., Fulbright, R. K., Magnuson, J. S., Van Dyke, J. A., \& Shankweiler, D. P. (2011). Unification of Sentence Processing via Ear and Eye: an fMRI study. Cortex, 47(4), 416-431. http://dx.doi.org/10.1016/i.cortex.2009.11.005

Braze, D., Shankweiler, D. P., Ni, W., \& Palumbo, L. C. (2002). Readers' Eye Movements Distinguish Anomalies of Form and Content. Journal of Psycholinguistic Research, 31(1), 25-44

Braze, D., Tabor, W., Shankweiler, D. P., \& Mencl, W. E. (2007). Speaking Up for Vocabulary: Reading Skill Differences in Young Adults. J Learn Disabil, 40(3), 226-243. http://dx.doi.org/10.1177/00222194070400030401

Byrne, B., Fielding-Barnsley, R., \& Ashley, L. (2000). Effects of preschool phoneme identity training after six years: Outcome level distinguished from rate of response. Journal of Educational Psychology, 92(4), 659-667. http://dx.doi.org/10.1037//0022-0663.92.4.659

Catts, H. W., Adlof, S. M., \& Weismer, S. E. (2006). Language deficits in poor comprehenders: A case for the simple view of reading. Journal of Speech Language and Hearing Research, 49(2), 278-293. http://dx.doi.org/10.1044/1092-4388(2006/023)

Cheung, H., \& Ng, L. K. H. (2003). Chinese Reading Development in Some Major Chinese Societies: an introduction. In C. McBride-Chang \& H.-C. Chen (Eds.), Reading Development in Chinese Children (pp. 3-17). Westport, Connecticut: Praeger Publishers/Greenwood Publishing Group

Coltheart, M., Curtis, B., Atkins, P., \& Haller, M. (1993). Models of reading aloud: Dual-route and paralleldistributed-processing approaches. Psychological Review, 100(4), 589-608. http://dx.doi.org/10.1037/0033-295x.100.4.589

Coltheart, M., \& Rastle, K. (1994). Serial Processing in Reading Aloud: Evidence for Dual-Route Models of Reading. Journal of Experimental Psychology: Human Perception and Performance, 20(6), 11971211. http://dx.doi.org/10.1037/0096-1523.20.6.1197

Coltheart, M., Rastle, K., Perry, C., Langdon, R., \& Ziegler, J. (2001). DRC: A Dual Route Cascaded Model of Visual Word Recognition and Reading Aloud. Psychological Review, 108(1), 204-256. http://dx.doi.org/10.1037/0033-295X.108.1.204

Constable, R. T., Pugh, K. R., Berroya, E., Mencl, W. E., Westerveld, M., Ni, W., \& Shankweiler, D. P. (2004). Sentence complexity and input modality effects in sentence comprehension: An fMRI study. Neuroimage, 22(1), 11-21. http://dx.doi.org/10.1016/j.neuroimage.2004.01.001

Coulmas, F. (1989). The Writing Systems of the World. Cambridge, Massachussetts: Blackwell

Cunningham, P. M. (1976). Teachers' correction responses to Black-dialect miscues which are nonmeaning-changing. Reading Research Quarterly, 12(4), 637-653.

http://dx.doi.org/10.2307/747445 
De Jong, P. F., \& Share, D. L. (2007). Orthographic Learning During Oral and Silent Reading. Scientific Studies of Reading, 11(1), 55-71. http://dx.doi.org/10.1207/s1532799xssr1101 4

DeFrancis, J. (1989). Visible Speech: the diverse oneness of writing systems

Dreyer, L. G., \& Katz, L. (1992). An examination of "The simple view of reading". In D. J. Leu \& C. K. Kinzer (Eds.), Yearbook of the National Reading Conference: Literacy research, theory and practice: Views from many perspectives (Vol. 41, pp. 169-175). Chicago, IL: National Reading Conference

Ellis, N. C., Natsume, M., Stavropoulou, K., Van Daal, V. H. P., Polyzoe, N., Tsipa, M.-L., \& Petalas, M. (2004). The effects of orthographic depth on learning to read alphabetic, syllabic and logographic scripts. Reading Research Quarterly, 39(4), 438-468. http://dx.doi.org/10.1598/RRQ.39.4.5

Engbert, R., Longtin, A., \& Kliegl, R. (2002). A dynamical model of saccade generation in reading based on spatially distributed lexical processing. Vision Research, 42(5), 621-636. http://dx.doi.org/10.1016/S0042-6989(01)00301-7

Feldman, L. B., Lukatela, G., \& Turvey, M. T. (1985). Effects of phonological ambiguity on beginning readers of Serbo-Croatian. Journal of Experimental Child Psychology, 39(3), 492-510. http://dx.doi.org/10.1016/0022-0965(85)90053-0

Frank, M. C., Tenenbaum, J. B., \& Gibson, E. (2013). Learning and Long-Term Retention of Large-Scale Artificial Languages. PLOS ONE, 8(1), e52500. http://dx.doi.org/10.1371/journal.pone.0052500

Frazier, L., \& Clifton, C., Jr. (1997). Construal: overview, motivation, and some new evidence. Journal of Psycholinguistic Research, 26(3), 277-295. http://dx.doi.org/10.1023/A:1025024524133

Frost, R. (1998). Toward a strong phonological theory of visual word recognition: True issues and false trails. Psychological Bulletin, 123(1), 71-99. http://dx.doi.org/10.1037//0033-2909.123.1.71

Frost, R., \& Katz, L. (1989). Orthographic depth and the interaction of visual and auditory processing in word recognition. Mem Cognit, 17(3), 302-310. http://dx.doi.org/10.3758/bf03198468

Frost, R., Katz, L., \& Bentin, S. (1987). Strategies for visual word recognition and orthographical depth: A multilingual comparison. Journal of Experimental Psychology: Human Perception and Performance, 13(1), 104-115. http://dx.doi.org/10.1037/0096-1523.13.1.104

Frost, S. J., Landi, N., Mencl, W. E., Sandak, R., Fulbright, R. K., Tejada, E. T., Jacobsen, L., Grigorenko, E. L., Constable, R. T., \& Pugh, K. R. (2009). Phonological awareness predicts activation patterns for print and speech. Annals of Dyslexia, 59(1), 78-97. http://dx.doi.org/10.1007/s11881-009-0024$\underline{y}$

García, J. R., \& Cain, K. (2014). Decoding and Reading Comprehension: A Meta-Analysis to Identify Which Reader and Assessment Characteristics Influence the Strength of the Relationship in English. Review of Educational Research, 84(1), 74-111. http://dx.doi.org/10.3102/0034654313499616

Glushko, R. J. (1979). The organization and activation of orthographic knowledge in reading aloud. Journal of Experimental Psychology: Human Perception and Performance, 5, 674-691. http://dx.doi.org/10.1037/0096-1523.5.4.674

Gong, T., Braze, D., Magnuson, J. S., Mencl, W. E., Tabor, W., Van Dyke, J. A., \& Shankweiler, D. P. (2016). Interactions between reading skills and lexical properties on on-line sentence reading. Gainesville, FL: Poster Presented at the 29th Annual CUNY Conference on Human Sentence Processing

Gough, P. B., Hoover, W. A., \& Peterson, C. L. (1996). Some observations on a simple view of reading. In C. Cornoldi \& J. Oakhill (Eds.), Reading comprehension difficulties: Processes and intervention (pp. 1-13). Mahwah, NJ: Lawrence Erlbaum Assoc

Gough, P. B., \& Tunmer, W. E. (1986). Decoding, reading, and reading disability. RASE: Remedial \& Special Education, 7(1), 6-10. http://dx.doi.org/10.1177/074193258600700104

Grigorenko, E. L., \& Naples, A. J. (Eds.). (2008). Single-Word Reading: behavioral and biological perspectives. New York: Lawrence Erlbaum Associates 
Hale, J. (2003). The information conveyed by words in sentences. Journal of Psycholinguistic Research, 32(2), 101-123. http://dx.doi.org/10.1023/A:1022492123056

Harm, M. W., \& Seidenberg, M. S. (1999). Phonology, reading acquisition, and dyslexia: insights from connectionist models. Psychological Review, 106(3), 491-528. http://dx.doi.org/10.1037/0033295X.106.3.491

Harm, M. W., \& Seidenberg, M. S. (2004). Computing the Meanings of Words in Reading: Cooperative Division of Labor Between Visual and Phonological Processes. Psychological Review, 111(3), 662720. http://dx.doi.org/10.1037/0033-295x.111.3.662

Hino, Y., \& Lupker, S. (2000). Effects of Word Frequency and Spelling-to-Sound Regularity in Naming with and without Preceding Lexical Decision. Journal of Experimental Psychology: Human Perception and Performance, 26(1), 166-183. http://dx.doi.org/10.1037//0096-1523.26.1.166

Hsu, C.-H., Tsai, J.-L., Lee, C.-Y., \& Tzeng, O. J. L. (2009). Orthographic combinability and phonological consistency effects in reading Chinese phonograms: An event-related potential study. Brain Lang, 108(1), 56-66. http://dx.doi.org/10.1016/j.bandl.2008.09.002

Hsu, S.-H., \& Huang, K.-C. (2000a). Effects of Word Spacing on Reading Chinese Text from a Video Display Terminal. Perceptual and Motor Skills, 90(1), 81-92. http://dx.doi.org/10.2466/pms.2000.90.1.81

Hsu, S.-H., \& Huang, K.-C. (2000b). Interword Spacing in Chinese Text Layout. Perceptual and Motor Skills, 91(2), 355-365. http://dx.doi.org/10.2466/pms.2000.91.2.355

Huey, E. B. (1908). The Psychology and Pedagogy of Reading. New York: MacMillan. http://dx.doi.org/10.2307/2177563

Husain, S., Vasishth, S., \& Srinivasan, N. (2015). Integration and prediction difficulty in Hindi sentence comprehension: Evidence from an eye-tracking corpus. Journal of Eye Movement Research

Inhoff, A. W. (1989). Parafoveal processing of words and saccade computation during eye fixations in reading. Journal of Experimental Psychology: Human Perception \& Performance, 15(3), 544-555. http://dx.doi.org/10.1037/0096-1523.15.3.544

Joseph, H. S. S. L., Liversedge, S. P., Blythe, H. I., White, S. J., \& Rayner, K. (2009). Word length and landing position effects during reading in children and adults. Vision Research, 49(16), 20782086. http://dx.doi.org/10.1016/i.visres.2009.05.015

Joshi, R. M., \& Aaron, P. G. (2000). The component model of reading: Simple view of reading made a little more complex. Reading Psychology, 21(2), 85-97. http://dx.doi.org/10.1080/02702710050084428

Just, M. A., \& Carpenter, P. A. (1978). Inference processes during reading: Reflections from eye fixations. In J. W. Sanders, D. F. Fisher \& R. A. Monty (Eds.), Eye Movements and the Higher Psychological Functions. Hillsdale, NJ: Lawrence Erlbaum Assoc

Just, M. A., \& Carpenter, P. A. (1980). A theory of reading: From eye fixations to comprehension. Psychological Review, 87(4), 329-354. http://dx.doi.org/10.1037/0033-295X.87.4.329

Kasisopa, B., G. Reilly, R., Luksaneeyanawin, S., \& Burnham, D. (2013). Eye movements while reading an unspaced writing system: The case of Thai. Vision Research, 86, 71-80. http://dx.doi.org/10.1016/i.visres.2013.04.007

Katz, L., \& Frost, R. (1992). The Reading Process is Different for Different Orthographies: The Orthographic Depth Hypothesis. Advances in Psychology, 94, 67-84. http://dx.doi.org/10.1016/S0166-4115(08)62789-2

Katz, L., Lee, C. H., Tabor, W., Frost, S. J., Mencl, W. E., Sandak, R., Rueckl, J., \& Pugh, K. R. (2005). Behavioral and neurobiological effects of printed word repetition in lexical decision and naming. Neuropsychologia, 43(14), 2068-2083. http://dx.doi.org/10.1016/j.neuropsychologia.2005.03.022 
Kavanagh, J. F. (1968). Proceedings of the Conference on Communicating by Language: the reading process; New Orleans, LA: February 11-13, 1968. Bethesda, MD: U.S. Dept. of Health, Education and Welfare.

Kintsch, W., \& Kintsch, E. (2005). Comprehension. In S. G. Paris \& S. A. Stahl (Eds.), Current Issues in Reading Comprehension Assessment (pp. 71-92). Mahwah, NJ: Lawrence Erlbaum Associates

Kliegl, R., Nuthmann, A., \& Engbert, R. (2006). Tracking the Mind during Reading: the influence of past, present, and future words on fixation durations. Journal of Experimental Psychology: General, 135(1), 12-35. http://dx.doi.org/10.1037/0096-3445.135.1.12

Labov, W. (1995). Can reading failure be reversed: A linguistic approach to the question. In V. L. Gadsden \& D. A. Wagner (Eds.), Literacy among African-American youth : issues in learning, teaching, and schooling (pp. 39-68). Cresskill, N.J.: Hampton Press

Landi, N. (2010). An examination of the relationship between reading comprehension, higher-level and lower-level reading sub-skills in adults. Reading and Writing, 23(6), 701-717. http://dx.doi.org/10.1007/s11145-009-9180-z

Lee, C.-Y., Tsai, J.-L., Kuo, W.-J., Yeh, T.-C., Wu, Y.-T., Ho, L.-T., Hung, D. L., Tzeng, O. J. L., \& Hsieh, J.-C. (2004). Neuronal correlates of consistency and frequency effects on Chinese character naming: an event-related fMRI study. Neuroimage, 23(4), 1235-1245. http://dx.doi.org/10.1016/j.neuroimage.2004.07.064

LeMoine, N. (2001). Language variation and literacy acquisition in African American students. In J. L. Harris, A. G. Kamhi \& K. E. Pollock (Eds.), Literacy in African American communities (pp. 169194). Mahwah, NJ: Lawrence Earlbaum Associates

Li, Q.-L., Bi, H.-Y., Wei, T.-Q., \& Chen, B.-G. (2011). Orthographic neighborhood size effect in Chinese character naming: Orthographic and phonological activations. Acta Psychologica, 136(1), 35-41. http://dx.doi.org/10.1016/j.actpsy.2010.09.012

Li, X., Rayner, K., \& Cave, K. R. (2009). On the segmentation of Chinese words during reading. Cognitive Psychology, 58(4), 525-552. http://dx.doi.org/10.1016/j.cogpsych.2009.02.003

Liberman, A. M. (1988). Reading Is Hard Just Because Listening Is Easy. Haskins Laboratories Status Report on Speech Research, 95-96(July-Dec), 145-150

Liberman, I. Y., Shankweiler, D., \& Liberman, A. M. (1989). The alphabetic principle and learning to read. In D. Shankweiler \& I. Y. Liberman (Eds.), Phonology and reading disability: Solving the reading puzzle (pp. 1-33). Ann Arbor, MI: The University of Michigan Press

Liu, Y., Reichle, E. D., \& Li, X. (2015). Parafoveal processing affects outgoing saccade length during the reading of Chinese. J Exp Psychol Learn Mem Cogn, 41(4), 1229-1236. http://dx.doi.org/10.1037/xIm0000057

Lukatela, G., Popadić, D., Ognjenović, p., \& Turvey, M. T. (1980). Lexical decision in a phonologically shallow orthography. Mem Cognit, 8(2), 124-132. http://dx.doi.org/10.3758/BF03213415

Lukatela, G., \& Turvey, M. T. (1980). Some experiments on Roman and Cyrillic alphabets. In J. F. Kavanagh \& R. L. Venezky (Eds.), Orthography, reading, and dyslexia. Baltimore, MD: University Park Press

MacDonald, M. C., Pearlmutter, N. J., \& Seidenberg, M. S. (1994). Syntactic ambiguity resolution as lexical ambiguity resolution. In C. Clifton, Jr., L. Frazier \& K. Rayner (Eds.), Perspectives on sentence processing (pp. 123-153). Hillsdale, NJ: Lawrence Erlbaum Assoc

Marslen-Wilson, W., Tyler, L. K., \& Koster, C. (1993). Integrative processes in utterance resolution. Journal of Memory and Language, 32(5), 647-666. http://dx.doi.org/10.1006/jmla.1993.1033

Marslen-Wilson, W. D., \& Welsh, A. (1978). Processing interactions and lexical access during word recognition in continuous speech. Cognitive Psychology, 10(1), 29-63. http://dx.doi.org/10.1016/0010-0285(78)90018-X 
Mattingly, I. G. (1972). Reading, the linguistic process, and linguistic awareness. In J. F. Kavanagh \& I. G. Mattingly (Eds.), Language by Ear and by Eye (pp. 133-147). Cambridge, MA: MIT Press

McClelland, J. L. (1979). On the time relations of mental processes: an examination of systems of processes in cascade. Psychological Review, 86(4), 287-330. http://dx.doi.org/10.1037/0033295X.86.4.287

McClelland, J. L., \& Rumelhart, D. E. (1981). An interactive activation model of context effects in letter perception: I. An account of basic findings. Psychological Review, 88(5), 375-407. http://dx.doi.org/10.1037/0033-295X.88.5.375

McConkie, G. W., Kerr, P. W., \& Dyre, B. P. (1994). What are "normal" eye movements during reading: Toward a mathematical description. In J. Ygge \& G. Lennerstrand (Eds.), Eye Movements in Reading. Amsterdam: Pergamon Press

McConkie, G. W., Kerr, P. W., Reddix, M. D., \& Zola, D. (1988). Eye movement control during reading: 1. The location of initial eye fixations on words. Vision Research, 28(10), 1107-1118. http://dx.doi.org/10.1016/0042-6989(88)90137-X

McConkie, G. W., Kerr, P. W., Reddix, M. D., \& Zola, D. (1989). Eye movement control during reading: II frequency of refixating a word. Perception and Psychophysics, 46(3), 245-253. http://dx.doi.org/10.3758/bf03208086

McKoon, G., \& Ratcliff, R. (1988). Contextually relevant aspects of meaning. Journal of Experimental Psychology: Learning, Memory, \& Cognition, 14(2), 331-343. http://dx.doi.org/10.1037/02787393.14.2.331

Michael, E. B., Keller, T. A., Carpenter, P. A., \& Just, M. A. (2001). fMRI investigation of sentence comprehension by eye and by ear: Modality fingerprints on cognitive processes. Human Brain Mapping, 13(4), 239-252. http://dx.doi.org/10.1002/hbm.1036

Morton, J. (1969). Interaction of Information in Word Recognition. Psychological Review, 76(2), 165-178. http://dx.doi.org/10.1037/h0027366

Morton, J. (1979). Facilitation in word recognition: Experiments causing change in the logogen model. In P. A. Kolers, M. E. Wrolstad \& H. Bouma (Eds.), Processing of Visible Language (pp. 259-268). New York: Plenum Press. http://dx.doi.org/10.1007/978-1-4684-0994-9 15

Morton, J. (1980). The logogen model and orthographic structure. In U. Frith (Ed.), Cognitive processes in spelling (pp. 117-132). London: Academic Press

Newman, E. H., Tardif, T., Huang, J., \& Shu, H. (2011). Phonemes matter: The role of phoneme-level awareness in emergent Chinese readers. Journal of Experimental Child Psychology, 108(2), 242259. http://dx.doi.org/10.1016/i.jecp.2010.09.001

Oakhill, J. V., \& Cain, K. (2011). The Precursors of Reading Ability in Young Readers: Evidence From a Four-Year Longitudinal Study. Scientific Studies of Reading(in press). http://dx.doi.org/10.1080/10888438.2010.529219

Padakannaya, P., \& Ramachandra, N. B. (2011). Reading Akshara: Indian Alphasyllabary. In P. McCardle, B. Miller, J. R. Lee \& O. J. L. Tzeng (Eds.), Dyslexica Across Languages (pp. 76-95). Baltimore, MD: Paul H. Brookes Publishing Co.

Patton Terry, N. (2012). Examining Relationships Among Dialect Variation and Emergent Literacy Skills. Communication Disorders Quarterly, 33(2), 67-77. http://dx.doi.org/10.1177/1525740110368846

Patton Terry, N., Connor, C. M., Thomas-Tate, S., \& Love, M. (2010). Examining relationships among dialect variation, literacy skills, and school context in first grade. Journal of Speech, Language \& Hearing Research, 53(1), 126-145. http://dx.doi.org/10.1044/1092-4388(2009/08-0058)

Patton Terry, N., \& Scarborough, H. S. (2011). The Phonological Hypothesis as a valuable framework for studying the relation of dialect variation to early reading skills. In S. Brady, D. Braze \& C. A. 
Fowler (Eds.), Explaining Individual Differences in Reading: Theory and Evidence. New York: Psychology Press

Paulesu, E. (2006). On the advantage of 'shallow' orthographies: number and grain size of the orthographic units or consistency per se? Developmental Science, 9(5), 443-444. http://dx.doi.org/10.1111/j.1467-7687.2006.00525.x

Perfetti, C., Liu, Y., Fiez, J. A., Nelson, J., Bolger, D. J., \& Tan, L.-H. (2007). Reading in two writing systems: Accommodation and assimilation of the brain's reading network. Bilingualism: Language and Cognition, 10(2), 131-146. http://dx.doi.org/10.1017/S1366728907002891

Perfetti, C. A. (2007). Reading Ability: Lexical Quality to Comprehension. Scientific Studies of Reading, 11(4), 357-383. http://dx.doi.org/10.1080/10888430701530730

Perfetti, C. A., Liu, Y., \& Tan, L. H. (2005). The Lexical Constituency Model: Some Implications of Research on Chinese for General Theories of Reading. Psychological Review, 112(1), 43-59. http://dx.doi.org/10.1037/0033-295X.112.1.43

Perfetti, C. A., \& Tan, L. H. (1998). The time course of graphic, phonological, and semantic activation in Chinese character identification. Journal of Experimental Psychology: Learning, Memory, and Cognition, 24(1), 101-118. http://dx.doi.org/10.1037/0278-7393.24.1.101

Plaut, D. C., McClelland, J. L., Seidenberg, M. S., \& Patterson, K. (1996). Understanding normal and impaired word reading: computational principles in quasi-regular domains. Psychological Review, 103(1), 56-115. http://dx.doi.org/10.1037/0033-295X.103.1.56

Pollatsek, A., Reichle, E. D., \& Rayner, K. (2006). Tests of the E-Z Reader model: exploring the interface between cognition and eye-movement control. Cogn Psychol, 52(1), 1-56. http://dx.doi.org/10.1016/j.cogpsych.2005.06.001

Pritchard, S. C., Coltheart, M., Marinus, E., \& Castles, A. (2016). Modelling the implicit learning of phonological decoding from training on whole-word spellings and pronunciations. Scientific Studies of Reading, 20(1), 49-63. http://dx.doi.org/10.1080/10888438.2015.1085384

Raney, G. E., \& Rayner, K. (1995). Word frequency effects and eye movements during two readings of a text. Canadian Journal of Experimental Psychology / Revue canadienne de psychologie experimentale, 49(2), 151-173. http://dx.doi.org/10.1037/1196-1961.49.2.151

Rao, C., Vaid, J., Srinivasan, N., \& Chen, H.-C. (2011). Orthographic characteristics speed Hindi word naming but slow Urdu naming: evidence from Hindi/Urdu biliterates. Reading and Writing, 24(6), 679-695. http://dx.doi.org/10.1007/s11145-010-9256-9

Rayner, K. (1975). The perceptual span and peripheral cues in reading. Cognitive Psychology, 7(1), 65-81. http://dx.doi.org/10.1016/0010-0285(75)90005-5

Rayner, K. (1998). Eye movements in reading and information processing: 20 years of research. Psychological Bulletin, 124(3), 372-422. http://dx.doi.org/10.1037/0033-2909.124.3.372

Rayner, K., Ardoin, S. P., \& Binder, K. S. (2013). Children's Eye Movements in Reading: A Commentary. School Psychology Review, 42(2), 223-233

Rayner, K., Carlson, M., \& Frazier, L. (1983). The interaction of syntax and semantics during sentence processing: eye movements in the analysis of semantically biased sentences. Journal of Verbal Learning and Verbal Behavior, 22(3), 358-374. http://dx.doi.org/10.1016/S0022-5371(83)90236$\underline{0}$

Rayner, K., Chace, K. H., Slattery, T. J., \& Ashby, J. (2006). Eye movements as reflections of comprehension processes in reading. Scientific Studies of Reading, 10(3), 241-255. http://dx.doi.org/10.1207/s1532799xssr1003 3

Rayner, K., Li, X., Juhasz, B. J., \& Yan, G. (2005). The effect of word predictability on the eye movements of Chinese readers. Psychon Bull Rev, 12(6), 1089-1093. http://dx.doi.org/10.3758/BF03206448 
Rayner, K., Li, X., \& Pollatsek, A. (2007). Extending the E-Z Reader model of Eye Movement Control to Chinese Readers. Cognitive Science, 31(6), 1021-1033.

http://dx.doi.org/10.1080/03640210701703824

Rayner, K., \& Morrison, R. E. (1981). Eye movements and identifying words in parafoveal vision. Bulletin of the Psychonomic Society, 17(3), 135-138. http://dx.doi.org/10.3758/bf03333690

Rayner, K., Sereno, S. C., Morris, R. K., Schmauder, A. R., \& Clifton, C., Jr. (1989). Eye movements and online language comprehension processes. Language and Cognitive Processes, 4(3-4), 21-49. http://dx.doi.org/10.1080/01690968908406362

Rayner, K., Well, A. D., Pollatsek, A., \& Bertera, J. H. (1982). The availability of useful information to the right of fixation in reading. Perception and Psychophysics, 31(6), 537-550. http://dx.doi.org/10.3758/BF03204186

Reicher, G. M. (1969). Perceptual Recognition as a Function of Meaningfulness of Stimulus Material. Journal of Experimental Psychology, 81(2), 275-280. http://dx.doi.org/10.1037/H0027768

Reichle, E. D., Liversedge, S. P., Pollatsek, A., \& Rayner, K. (2009). Encoding multiple words simultaneously in reading is implausible. Trends in Cognitive Sciences, 13(3), 115-119. http://dx.doi.org/10.1016/j.tics.2008.12.002

Reichle, E. D., Pollatsek, A., Fisher, D. L., \& Rayner, K. (1998). Toward a model of eye movement control in reading. Psychological Review, 105(1), 125-157. http://dx.doi.org/10.1037/0033295X.105.1.125

Reichle, E. D., Pollatsek, A., \& Rayner, K. (2006). E-Z Reader: A cognitive-control, serial-attention model of eye-movement behavior during reading. Cognitive Systems Research, 7(1), 4-22. http://dx.doi.org/10.1016/j.cogsys.2005.07.002

Reichle, E. D., Pollatsek, A., \& Rayner, K. (2012). Using E-Z Reader to simulate eye movements in nonreading tasks: a unified framework for understanding the eye-mind link. Psychological Review, 119(1), 155-185. http://dx.doi.org/10.1037/a0026473

Reichle, E. D., Warren, T., \& McConnell, K. (2009). Using E-Z Reader to model the effects of higher level language processing on eye movements during reading. Psychon Bull Rev, 16(1), 1-21. http://dx.doi.org/10.3758/PBR.16.1.1

Reilly, R. G., Aranyanak, I., Yu, L., Yan, G., \& Tang, S. (2011). Eye movement control in reading Thai and Chinese. Xinli Yu Xingwei Yanjiu, 9(1), 35-44

Reilly, R. G., \& O'Regan, J. K. (1998). Eye Movement Control during Reading: A simulation of some wordtargeting strategies. Vision Research, 38(2), 303-317. http://dx.doi.org/10.1016/S00426989(97)87710-3

Rimzhim, A., Katz, L., \& Fowler, C. A. (2014). Brāhmī-derived orthographies are typologically Āksharik but functionally predominantly alphabetic. Writing Systems Research, 6(1), 41-53. http://dx.doi.org/10.1080/17586801.2013.855618

Rueckl, J. G. (2016). Toward a theory of variation in the organization of the word reading system. Scientific Studies of Reading, 20(1), 86-97. http://dx.doi.org/10.1080/10888438.2015.1103741

Rumelhart, D. E., \& McClelland, J. L. (1982). An interactive activation model of context effects in letter perception: II. The contextual enhancement effect and some tests and extensions of the model. Psychological Review, 89(1), 60-94. http://dx.doi.org/10.1037/0033-295X.89.1.60

Saffran, J. R., Newport, E. L., \& Aslin, R. N. (1996). Word Segmentation: The Role of Distributional Cues. Journal of Memory and Language, 35(4), 606-621. http://dx.doi.org/10.1006/jmla.1996.0032

Schmalz, X., Marinus, E., Coltheart, M., \& Castles, A. (2015). Getting to the bottom of orthographic depth. Psychon Bull Rev. http://dx.doi.org/10.3758/s13423-015-0835-2

Seidenberg, M. S., \& McClelland, J. L. (1989). A distributed, developmental model of word recognition and naming. Psychological Review, 96(4), 523-568. http://dx.doi.org/10.1037/0033$\underline{295 X .96 .4 .523}$ 
Seymour, P. H. K., Aro, M., \& Erskine, J. M. (2003). Foundation literacy acquisition in European orthographies. British Journal of Psychology, 94(2), 143.

http://dx.doi.org/10.1348/000712603321661859

Shankweiler, D. P., Mencl, W. E., Braze, D., Tabor, W., Pugh, K. R., \& Fulbright, R. K. (2008). Reading Differences and Brain: Cortical Integration of Speech and Print in Sentence Processing Varies with Reader Skill. Dev Neuropsychol, 33(6), 745-776. http://dx.doi.org/10.1080/87565640802418688

Share, D. L. (1995). Phonological recoding and self-teaching: sine qua non of reading acquisition. Cognition, 55(2), 151-218. http://dx.doi.org/10.1016/0010-0277(94)00645-2

Share, D. L. (2008). On the Anglocentricities of Current Reading Research and Practice: The Perils of Overreliance on an "Outlier" Orthography. Psychological Bulletin, 134(4), 584-615. http://dx.doi.org/10.1037/0033-2909.134.4.584

Share, D. L. (2011). On the Role of Phonology in Reading Acquisition: the self-teaching hypothesis. In S. A. Brady, D. Braze \& C. A. Fowler (Eds.), Explaining Individual Differences in Reading: Theory and Evidence (pp. 45-68). New York, NY: Psychology Press

Share, D. L. (2014). Alphabetism in Reading Science. Frontiers in Psychology, 5(752). http://dx.doi.org/10.3389/fpsyg.2014.00752

Sheridan, H., Rayner, K., \& Reingold, E. M. (2013). Unsegmented text delays word identification: Evidence from a survival analysis of fixation durations. Visual Cognition, 21(1), 38-60. http://dx.doi.org/10.1080/13506285.2013.767296

Sheridan, H., \& Reichle, E. D. (2015). An Analysis of the Time Course of Lexical Processing During Reading. Cogn Sci. http://dx.doi.org/10.1111/cogs.12246

Shu, H., Chen, X., Anderson, R. C., Wu, N., \& Xuan, Y. (2003). Properties of School Chinese: Implications for Learning to Read. Child Development, 74(1), 27-47. http://dx.doi.org/10.1111/1467$\underline{8624.00519}$

Slattery, T. J., \& Rayner, K. (2013). Effects of intraword and interword spacing on eye movements during reading: Exploring the optimal use of space in a line of text. Attention, Perception, \& Psychophysics, 75(6), 1275-1292. http://dx.doi.org/10.3758/s13414-013-0463-8

Staub, A., \& Rayner, K. (2007). Eye movements and on-line comprehension processes. In M. G. Gaskell \& G. T. M. Altmann (Eds.), The Oxford handbook of psycholinguistics: The Oxford University Press

Treiman, R., Mullennix, J., Bijeljac-Babic, R., \& Richmond-Welty, E. D. (1995). The Special Role of Rimes in the Description, Use, and Acquisition of English Orthography. Journal of Experimental Psychology-General, 124(2), 107-136. http://dx.doi.org/10.1037/0096-3445.124.2.107

Tunmer, W. E., \& Chapman, J. W. (2012). The Simple View of Reading Redux: Vocabulary Knowledge and the Independent Components Hypothesis. J Learn Disabil, 45(5), 453-466. http://dx.doi.org/10.1177/0022219411432685

Valle, A., Binder, K. S., Walsh, C. B., Nemier, C., \& Bangs, K. E. (2013). Eye Movements, Prosody, and Word Frequency Among Average-and High-Skilled Second-Grade Readers. School Psychology Review, 42(2), 171-190

Van Orden, G. C. (1990). Word identification in reading and the promise of subsymbolic psycholinguistics. Psychological Review, 97(4), 488-522. http://dx.doi.org/10.1037/0033295X.97.4.488

Vitu, F., O'Regan, J. K., \& Mittau, M. (1990). Optimal Landing Position in Reading Isolated Words and Continuous Text. Perception \& Psychophysics, 47(6), 583-600. http://dx.doi.org/10.3758/BF03203111

Wang, Y., Yin, L., \& McBride, C. (2015). Unique predictors of early reading and writing: A one-year longitudinal study of Chinese kindergarteners. Early Childhood Research Quarterly, 32, 51-59. http://dx.doi.org/10.1016/j.ecresq.2015.02.004 
Warren, T., Reichle, E. D., \& Patson, N. D. (2011). Lexical and Post-Lexical Complexity Effects on Eye Movements in Reading. Journal of Eye Movement Research, 4(1), 1-10

Wheeler, D. D. (1970). Processes in word recognition. Cognitive Psychology, 1(1), 59-85. http://dx.doi.org/10.1016/0010-0285(70)90005-8

Wolfram, W. (2006). Variation and Language: an overview. In E. K. Brown (Ed.), Encyclopedia of Language and Linguistics. Oxford: Elsevier

Xu, Y., Pollatsek, A., \& Potter, M. C. (1999). The activation of phonology during silent Chinese word reading. Journal of Experimental Psychology: Learning, Memory, and Cognition, 25(4), 838-857. http://dx.doi.org/10.1037/0278-7393.25.4.838

Yan, G., Tian, H., Bai, X., \& Rayner, K. (2006). The effect of word and character frequency on the eye movements of Chinese readers. British Journal of Psychology, 97(Pt 2), 259-268. http://dx.doi.org/10.1348/000712605X70066

Yang, J. F., McCandliss, B. D., Shu, H., \& Zevin, J. D. (2009). Simulating language-specific and languagegeneral effects in a statistical learning model of Chinese reading. Journal of Memory and Language, 61(2), 238-257. http://dx.doi.org/10.1016/j.jml.2009.05.001

Zhang, J., McBride-Chang, C., Tong, X., Wong, A. M. Y., Shu, H., \& Fong, C. Y. C. (2012). Reading with meaning: The contributions of meaning-related variables at the word and subword levels to early Chinese reading comprehension. Reading and Writing, 25(9), 2183-2203. http://dx.doi.org/10.1007/s11145-011-9353-4

Zhang, S., \& Perfetti, C. A. (1993). The tongue twister effect in reading Chinese. Journal of Experimental Psychology: Learning, Memory, and Cognition, 19(5), 1082-1093. http://dx.doi.org/10.1037//0278-7393.19.5.1082

Ziegler, J., Perry, C., \& Coltheart, M. (2003). Speed of lexical and nonlexical processing in French: The case of the regularity effect. Psychon Bull Rev, 10(4), 947-953. http://dx.doi.org/10.3758/BF03196556

Ziegler, J. C., Perry, C., \& Coltheart, M. (2000). The DRC model of visual word recognition and reading aloud: An extension to German. European Journal of Cognitive Psychology, 12(3), 413-430. http://dx.doi.org/10.1080/09541440050114570 